\title{
04.1
}

\section{Исследование условий пробоя газов в пористом диэлектрике}

\author{
(ㄷ Д.Д. Медведев ${ }^{1}$, Н.К. Белов ${ }^{2}$, О.О. Гранкина ${ }^{1}$, А.А. Книжник ${ }^{1}$, С.В. Коробцев ${ }^{1}$, Б.В. Потапкин ${ }^{1}$ \\ ${ }^{1}$ Национальный исследовательский центр „Курчатовский институт“, Москва, Россия \\ ${ }^{2}$ Объединенный институт высоких температур РАН, Москва, Россия \\ E-mail: dm_medvedev@mail.ru
}

Поступило в Редакцию 10 июня 2021г.

В окончательной редакции 12 июля 2021 г.

Принято к публикации 13 июля 2021 г.

Известно, что плазменная обработка пористых полимерных материалов является перспективным методом создания новых материалов, которые могут найти применение в различных прикладных задачах, в том числе в медицине, при разработке новых типов биосовместимых и биоразлагаемых полимерных материалов. Исследованы процессы плазменной обработки пористых полимерных материалов в зависимости от размера и типа пор для уточнения условий пробоя и оптимизации процесса обработки. Предложена удобная полуэмпирическая модель развития пробоя в пористом диэлектрике.

Ключевые слова: плазменная обработка диэлектрика, закон Пашена в пористой среде, напряжение пробоя пористого материала.

DOI: 10.21883/PJTF.2021.20.51614.18914

Плазменная обработка полимерных материалов известный инструмент для модификации свойств их поверхности (увеличение гидрофильности и адгезии красителей и клеящих материалов). Обработка не только поверхности, но и всего объема пористых полимерных материалов может дать гораздо больший эффект и использоваться для создания новых материалов, которые могут найти применение в различных прикладных задачах, в том числе при разработке новых типов биосовместимых и биоразлагаемых полимерных материалов.

Плазменная обработка пор в полимерных материалах предполагает зажигание плазмы внутри этих пор или, другими словами, электрический пробой газа между электродами, впервые описанный Пашеном [1]. Закон Пашена продолжает уточняться и модифицироваться [2-5] для практически важных условий, в частности для микрозазоров. Целью настоящей работы является исследование процесса пробоя в пористом диэлектрике, который можно рассматривать как пробой группы последовательных микрозазоров при достижении в каждом из них пашеновского пробойного напряжения.

Эксперименты проводились в разрядной камере с входом и выходом газа, состоящей из прозрачной верхней половины и заземленного металлического дна с уплотнительным кольцом из силиконовой резины. Роль высоковольтного прозрачного электрода со стеклянным барьером выполнял закрытый стеклянный сосуд с плоским дном диаметром $20 \mathrm{~mm}$ с водным раствором $\mathrm{NaCl}$ с проводимостью $20 \mathrm{mS} / \mathrm{cm}$. Обрабатываемый образец помещался в зазор толщиной $2.5 \mathrm{~mm}$ между высоковольтным и заземленным электродами.

Для исследования процесса пробоя в пористом материале, помещенном в разрядный зазор, снимались осциллограммы напряжения и тока, протекающего через систему электродов. Для сравнения также были полу- чены осциллограммы при пустом зазоре. Эксперименты проводились на образцах пористого полиуретана с полностью связанными порами и пористого полистирола с не полностью связанными порами на воздухе при разном давлении $(p)$.

На рис. 1 приведен пример осциллограммы измеренного тока и напряжения для пустого зазора и образца пористого полиуретана со связанными порами со средним размером $0.17 \mathrm{~mm}$. На рис. 1 также приведены рассчитанные значения емкостного тока произведения производной напряжения по времени и емкости электродной системы и подводящих проводов $(2.9 \mathrm{pF})$. Емкостный ток позволяет вычислить ток разряда (разность измеренного и емкостного тока) для более точного определения момента и напряжение пробоя.

Также из осциллограмм тока и напряжения рассчитывались значения протекшего заряда и вложенной энергии в зависимости от времени. При использовании материала с частично изолированными порами значения тока, заряда и вложенной энергии оказывались на порядок ниже, так как реально в пробое участвовала только открытая часть пор, где давление понижалось до уровня окружающего.

Полученные данные по напряжению пробоя сравнивались с расчетными, полученными в приближении одинаковых пор с размером, равным среднему размеру пор в материале, определенному из микрофотографии. Для расчета использовалась формула Пашена, адаптированная для барьерного разряда в микрозазорах, описанная в работах $[4,5]$ :

$$
\begin{gathered}
U=\frac{B p d}{\ln (\text { Apd })-\ln \left(\ln \left(1+\frac{1}{\gamma}\right)\right)}, \\
A=14.73(\text { Torr } \cdot \mathrm{cm})^{-1}, \\
B=450 \mathrm{~V} /(\text { Torr } \cdot \mathrm{cm})
\end{gathered}
$$



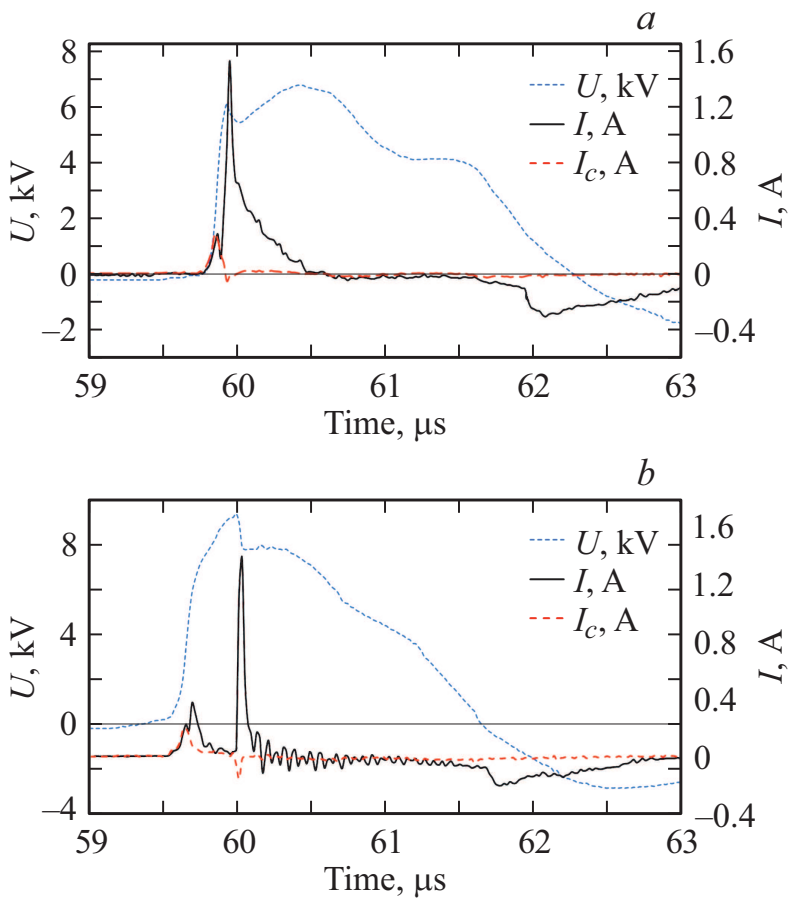

Рис. 1. Осциллограммы напряжения $U$, измеренного тока $I$ и емкостного тока $I_{c}$ для воздушного зазора $(a)$ и зазора, заполненного пористым полиуретаном с полностью связанными порами $(b)$. Среда - воздух, давление 80 Torr, зазор $0.25 \mathrm{~cm}$.

с переменным значением $\gamma$, убывающим при увеличении $p d$ обратно пропорционально его квадрату:

$$
\gamma=\frac{1.67 \cdot 10^{-3}(\text { Torr } \cdot \mathrm{cm})^{2}}{(p d)^{2}}
$$

В качестве толщины зазора $(d)$ берется размер поры, a полное напряжение рассчитывается как произведение напряжения на одной поре на их количество, укладывающееся в зазор. Такие зависимости напряжения пробоя в разрядном зазоре, заполненном пористым диэлектриком, для различных размеров пор представлены на рис. 2.

Для экспериментальных данных брался средний размер пор. Приведены также кривые для воздушного промежутка без пористого диэлектрика (cl. gap): среда воздух, зазор $0.25 \mathrm{~cm}$. Такое простое приближение дает неплохое совпадение с экспериментальными результатами, несмотря на существенное отличие исследуемого диапазона $p d$ от того, в котором была первоначально получена формула Пашена $[4,5]$, используемая в расчетах. Для более детального описания процесса пробоя и лучших оценок его параметров была разработана простая полуэмпирическая модель, описывающая пробой пористого диэлектрика с гауссовым распределением пор по размерам, параметры которого подбираются близкими к реальному (полученному при помощи микрофотографий). В модели поры разного размера формируют вертикальные столбики или последовательно соединенные конденсаторы, напряжение на которых рассчитывалось с учетом их емкости. При превышении пашеновского порога пробоя [4,5] поры напряжение на ней приравнивалось к нулю и пересчитывались напряжения на остальных порах до момента прекращения пробоев. В результате рассчитывались протекший заряд и вложенная энергия в зависимости от приложенного напряжения. Результаты моделирования для полистирола (средний диаметр пор $0.17 \mathrm{~mm}$ ) и полиуретана (средний диаметр пор $0.36 \mathrm{~mm}$ ) приведены на рис. 3.

Закрытость части пор в реальном образце резко снижает реальный ток и протекший заряд по сравнению с расчетными величинами, поскольку реально пробой происходит только в открытой части пор, где давление воздуха ниже. Однако расчетное значение напряжения пробоя, соответствующее значению напряжения, когда про-

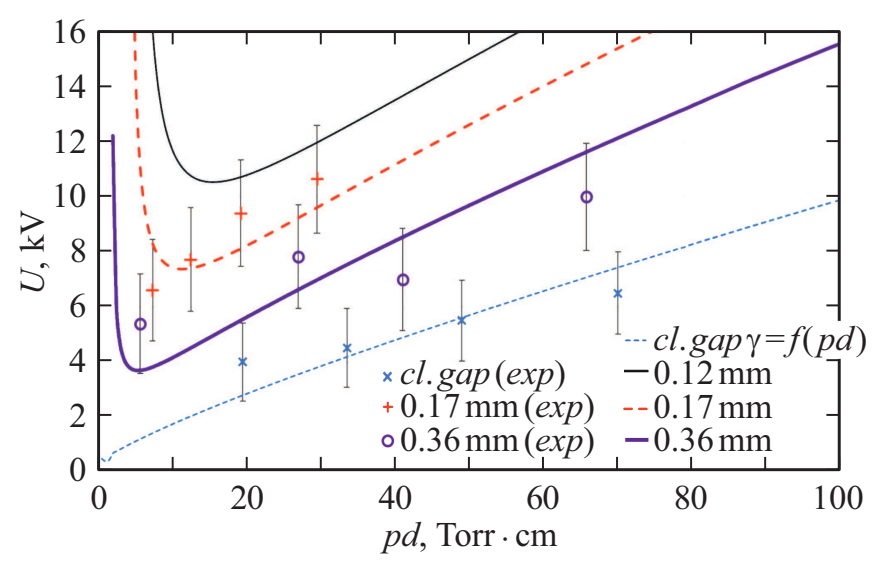

Рис. 2. Сравнение оценки зависимости напряжения пробоя разрядного промежутка, заполненного пористым диэлектриком с порами размером $0.12,0.17,0.36 \mathrm{~mm}$, и воздушного разрядного промежутка (cl. gap) от произведения давления на толщину зазора для различных размеров пор с экспериментальными данными (ехр).

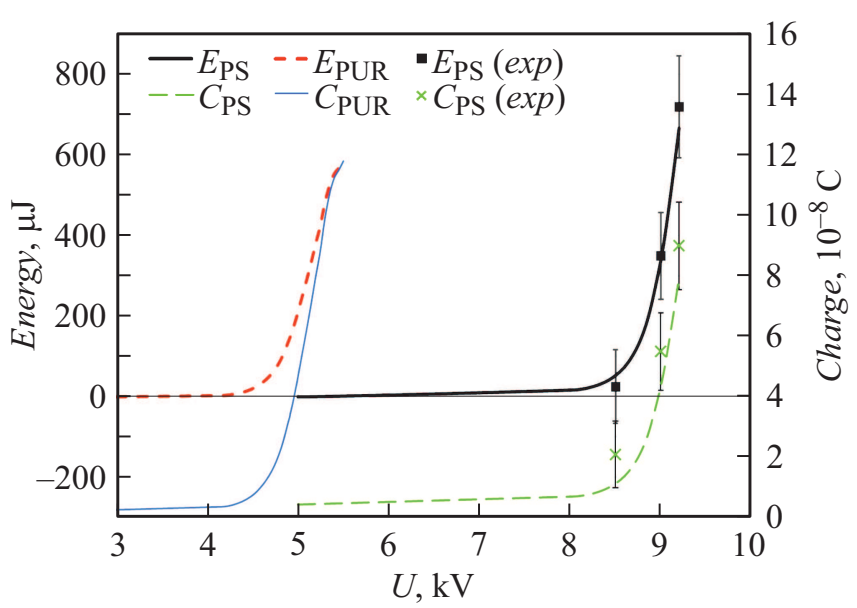

Рис. 3. Расчет вложенной энергии и протекшего заряда от напряжения на разрядном промежутке, заполненном пористым полистиролом (PS, средний диаметр пор $0.17 \mathrm{~mm}$ ) и пористым полиуретаном (PUR, средний диаметр пор $0.36 \mathrm{~mm}$ ). Среда воздух, давление 80 Torr, зазор $0.25 \mathrm{~cm}$. 
тек существенный (например, 20\% от максимального) заряд, достаточно близко к измеренному экспериментально.

Для материала с открытыми порами модель дает хорошее количественное совпадение протекшего заряда $(6.6 \mu \mathrm{C}-$ расчет, $7.5 \mu \mathrm{C}-$ эксперимент) и вложенной энергии ( $8.0 \mathrm{~mJ}$ - расчет, $7.2 \mathrm{~mJ}$ - эксперимент) в момент, когда напряжение достигло максимального значения $9.2 \mathrm{kV}$.

Таким образом, можно сделать следующие выводы.

1. В работе были проведены эксперименты по определению пробойного напряжения в образцах из пенополистирола и пористого полиуретана в импульсном барьерном разряде при разных давлениях воздуха.

2. Выполнено исследование электрических параметров разряда в пористом материале в зависимости от размера и типа пор.

3. Проведены оценочные расчеты кривых Пашена для зазора, заполненного пористым диэлектриком в приближении одинаковых пор. Получено хорошее совпадение с результатами эксперимента.

4. Предложена удобная полуэмпирическая модель развития пробоя в пористом диэлектрике с распределением пор по размерам, близким к реальному. Получено хорошее количественное совпадение с экспериментом для величины напряжения пробоя. Для материала со связанными порами получено хорошее количественное согласие с экспериментом для величин протекшего заряда и вложенной энергии.

\section{Финансирование работы}

Работа выполнена при частичной поддержке НИЦ „Курчатовский институт“ (приказ № 2073 от 09.10.2020 г.).

\section{Конфликт интересов}

Авторы заявляют, что у них нет конфликта интересов.

\section{Список литературы}

[1] F. Paschen, Ann. Phys., 273 (5), 69 (1889). DOI: $10.1002 /$ andp. 18892730505

[2] L.F. Berzak, S.E. Dorfman, S.P. Smith, Paschen's law in air and noble gases (Lawrence Berkeley National Laboratory, 2006).

[3] A.M. Loveless, A.L. Garner, Phys. Plasmas, 24 (11), 113522 (2017). DOI: $10.1063 / 1.5004654$

[4] А.А. Книжник, С.В. Коробцев, Д.Д. Медведев, Б.В. Потапкин, Н.К. Белов, Письма в ЖЭТФ, 111 (5), 305 (2020). DOI: $10.31857 / \mathrm{S} 0370274 \mathrm{X} 20050069$

[5] A.A. Knizhnik, S.V. Korobtsev, D.D. Medvedev, B.V. Potapkin, N.K. Belov, O.O. Grankina, AIP Adv., 10 (8), 085119 (2020). DOI: $10.1063 / 5.0010056$ 